Research Article

\title{
Reaction Kinetics of Chlorine Corrosion to Heating Surfaces during Coal and Biomass Cofiring
}

\author{
Yongzheng Wang $(D$, Yu Sun, Maozhen Yue, and Yungang Li \\ School of Energy and Power Engineering, Shandong University, Jinan 250061, China \\ Correspondence should be addressed to Yongzheng Wang; sddxwyz@163.com
}

Received 1 November 2019; Revised 30 December 2019; Accepted 16 January 2020; Published 12 February 2020

Guest Editor: Ningbo Gao

Copyright (c) 2020 Yongzheng Wang et al. This is an open access article distributed under the Creative Commons Attribution License, which permits unrestricted use, distribution, and reproduction in any medium, provided the original work is properly cited.

\begin{abstract}
The high content of chlorine in biomass will cause serious ash deposition and corrosion problems on the heating surface in boiler, reduce heat transfer efficiency, and endanger the boiler operation safety. On the basis of discussing the mechanism of chlorine corrosion to heating surface in the boiler, the temperature, atmosphere, and fouling in the boiler are simulated by high-temperature reaction device. Reaction kinetics of chlorine corrosion to heating surfaces during coal and biomass cofiring was studied by the weight gain method, which provides a theoretical basis for solving the problem of corrosion and improving the safety of boiler operation. The results show that the weight gain caused by corrosion increases with time, and its curve is in accordance with the parabola. In the early stage, the corrosion rate is very fast, and the corrosion gradually slows down after the protective layer is formed. The mixing ratio of straw biomass increases, and the corrosion rate increases proportionally. With the increase in temperature, the rate of corrosion reaction increases continuously. When the temperature exceeds $600^{\circ} \mathrm{C}$, the corrosion reaction rate increases greatly. The concentration of $\mathrm{HCl}$ in the gas phase increases and the rate of corrosion reaction increases rapidly. Under the constant temperature, the reaction kinetics characteristics of chlorine corrosion were analyzed by model function matching. The best kinetic model function for calculating the kinetic parameters was determined, and the kinetic equation of corrosion reaction was established to quantitatively characterize the corrosion reaction.
\end{abstract}

\section{Introduction}

Fossil fuels such as coal continue to be consumed and result in the environmental problems that are becoming increasingly prominent. Biomass, a kind of green renewable energy source, has drawn more attention all over the world [1]. Biomass resource in China, especially crop straw, is abundant. Besides, cofiring technology applied in coal-fired boilers is a promising biomass utilization approach [2]. If biomass is used in large power plants and directly blended with coal to combust in coal-fired boiler, existing facilities of the power plant can be utilized without a large amount of investment; therefore, it is a low-cost and low-risk way to utilize renewable energy at current stage $[3,4]$.

During cofiring of biomass and coal, especially large amounts of straw biomass and coal blended to combustion, owing to high contents of alkali metal and chlorine in straw biomass, it would lead to deposition, slagging, and corrosion problems of metal heating surfaces which could seriously harm the safety and economy of boiler equipment and consequently limit large-scale use of biomass in power plants [5-7]. The corrosion of heating surface metal is divided into gas phase corrosion and ash corrosion. Gases such as $\mathrm{HCl}$ and $\mathrm{Cl}_{2}$ cause gas phase corrosion. In an oxidizing atmosphere, the metal surface is oxidized to an oxide film, which prevents corrosion from proceeding further [8]. However, the gas chloride also reacts with the metal to form a metal chloride. The metal chloride is oxidized and releases $\mathrm{Cl}_{2}$ again, and $\mathrm{Cl}_{2}$ diffuses into the gas for a new round of reaction, which is named active oxidative corrosion [9]. In a reducing atmosphere, the metal oxide film is absent, and the $\mathrm{Cl}_{2}$ can directly react with the metal. Ash deposition is the main cause of high-temperature corrosion [10], due to the large amount of $\mathrm{KCl}$ in the ash. The sedimentary layer of ash is divided into three layers, wherein the innermost main component is $\mathrm{KCl}$, the middle layer is $\mathrm{K}_{2} \mathrm{SO}_{4}$, and the 
outermost layer is mainly $\mathrm{SiO}_{2}$ [11]. It was found that the precipitation of $\mathrm{K}$ in wheat straw, rice straw, and rice husk was higher, and the precipitation of $\mathrm{Cl}$ in corn stalk and cotton stalk was higher [12]. $\mathrm{KCl}$ can directly react with the oxide film on the metal surface to form $\mathrm{Cl}_{2}$, metal oxides, and potassium compounds $[13,14]$.

The current related research mainly focusing on characteristics of combustion, pollutant emission, and ash fusion during cofiring of biomass and coal [15-18] seldom involves in corrosion problem of metal heating surfaces. Hence, the problems of chlorine corrosion to metal heating surfaces will be studied in this paper to explore the process mechanism and reaction kinetics characteristics of chloride corrosion to metal heat delivery surface in large coal-fired power plant boiler during biomass and coal cofiring. It can quantitatively analyze the corrosion process under constant temperature conditions, provide a reference for the optimization of boiler operating parameters, and provide the theoretical foundation for extensive and efficient use of biomass resources.

\section{Chlorine Corrosion Mechanism}

During cofiring of biomass and coal, the corrosion to metal heating surfaces in boiler was mainly related to chlorine and sulfur in fuels [19]. The precondition that influences the corrosion most is the molar ratio between sulfur and chlorine in the fuel [20]. When the amount of biomass blended to coal was large, corrosion effect was given priority to chloride corrosion to metal. Studies found that chlorine in biomass fuel played an important role in high-temperature corrosion to metal heat delivery surface in boiler. When the content of chlorine in biomass fuel reached a certain value, the corrosion effect of chlorine would be greater than that of sulfur in biomass fuel. Some studies indicated that hightemperature corrosion involving chlorine tended to be serious when the content of chlorine in the fuel was more than $0.3 \%$ [21]. Chlorine mainly presented in the form of $\mathrm{HCl}$, $\mathrm{Cl}_{2}, \mathrm{KCl}$, and $\mathrm{NaCl}$ during cofiring of biomass and coal, and corrosion effect of $\mathrm{HCl}$ in flue gas was principal. Experiment results showed that $95 \%$ of chlorine in fuel released with converting into $\mathrm{HCl}$ during flue combusting [22].

$\mathrm{HCl}$ releasing from fuel combustion is gaseous corrosion medium with high activity. It can directly react with metal heat delivery surfaces and actively involves in corrosion to $\mathrm{Fe}, \mathrm{FeO}, \mathrm{Fe}_{2} \mathrm{O}_{3}, \mathrm{Fe}_{3} \mathrm{O}_{4}$, and $\mathrm{Cr}_{2} \mathrm{O}_{3}$ under high-temperature condition:

$$
\begin{gathered}
\mathrm{Fe}+2 \mathrm{HCl} \longrightarrow \mathrm{FeCl}_{2}+\mathrm{H}_{2} \\
\mathrm{FeO}+2 \mathrm{HCl} \longrightarrow \mathrm{FeCl}_{2}+\mathrm{H}_{2} \mathrm{O} \\
\mathrm{Fe}_{2} \mathrm{O}_{3}+2 \mathrm{HCl}+\mathrm{CO} \longrightarrow \mathrm{FeO}+\mathrm{FeCl}_{2}+\mathrm{H}_{2} \mathrm{O}+\mathrm{CO}_{2} \\
\mathrm{Fe}_{3} \mathrm{O}_{4}+2 \mathrm{HCl}+\mathrm{CO} \longrightarrow 2 \mathrm{FeO}+\mathrm{FeCl}_{2}+\mathrm{H}_{2} \mathrm{O}+\mathrm{CO}_{2} \\
\mathrm{Cr}_{2} \mathrm{O}_{3}+4 \mathrm{HCl}+\mathrm{H}_{2} \longrightarrow 2 \mathrm{CrCl}_{2}+3 \mathrm{H}_{2} \mathrm{O}
\end{gathered}
$$

Owing to the presence of $\mathrm{HCl}$, the protective oxide film on the surface of the metal can be destroyed. It makes the transmission rate of gaseous corrosion medium toward metal interface increase and consequently leads to corrosion to metal base.

When the surface temperature on the pipe wall exceeds the melting point temperature of $\mathrm{FeCl}_{2}, \mathrm{FeCl}_{2}$ will evaporate into gas phase. When $\mathrm{FeCl}_{2}$ escapes into flue gas, due to oxygen pressure increasing along the way, $\mathrm{FeCl}_{2}$ is oxidized by $\mathrm{O}_{2}$ to form $\mathrm{Cl}_{2}$ :

$$
4 \mathrm{FeCl}_{2}+3 \mathrm{O}_{2} \longrightarrow 2 \mathrm{Fe}_{2} \mathrm{O}_{3}+4 \mathrm{Cl}_{2}
$$

The formed $\mathrm{Cl}_{2}$ permeates into the metal surface and reacts with $\mathrm{Fe}, \mathrm{FeCl}_{2}$, and $\mathrm{Cr}_{2} \mathrm{O}_{3}$ as follows:

$$
\begin{gathered}
2 \mathrm{Fe}+3 \mathrm{Cl}_{2} \longrightarrow 2 \mathrm{FeCl}_{3} \\
2 \mathrm{FeCl}_{2}+\mathrm{Cl}_{2} \longrightarrow 2 \mathrm{FeCl}_{3} \\
2 \mathrm{Cr}_{2} \mathrm{O}_{3}+4 \mathrm{Cl}_{2}+\mathrm{O}_{2} \longrightarrow 4 \mathrm{CrO}_{2} \mathrm{Cl}_{2}
\end{gathered}
$$

$\mathrm{FeCl}_{3}$ formed in the above reaction, which is of low melting point $\left(303^{\circ} \mathrm{C}\right)$ and high vapor pressure $(1670 \mathrm{~Pa})$, is very easy to volatilize under the surface temperature of the metal. It causes gaps in the protective film and the film becomes loose and significantly reduces the transmission resistance of active gaseous corrosion medium to metal base interface. In addition, corrosion products are more likely to spall off, thereby promoting the reaction process of corrosion to metal.

Then formed $\mathrm{FeCl}_{3}$ will be transformed into $\mathrm{Cl}_{2}$ under certain conditions:

$$
4 \mathrm{FeCl}_{3}+3 \mathrm{O}_{2} \longrightarrow 2 \mathrm{Fe}_{2} \mathrm{O}_{3}+6 \mathrm{Cl}_{2}
$$

In the above cyclic reaction process, $\mathrm{Cl}_{2}$ with strong oxidization constantly erodes iron and its compounds. Hence, the reaction process of chlorine corrosion is of repetitive features.

Furthermore, chloride and sulfur oxides will coexist during cofiring of biomass and coal, by means of $\mathrm{O}_{2}$ and $\mathrm{H}_{2} \mathrm{O}$, and it not only accelerates the formation of sulfate but also contributes to produce $\mathrm{HCl}$ and $\mathrm{Cl}_{2}$, which greatly increases the extent of high-temperature corrosion [23]:

$$
\begin{gathered}
2 \mathrm{NaCl}+\mathrm{SO}_{3}+\mathrm{H}_{2} \mathrm{O} \longrightarrow \mathrm{Na}_{2} \mathrm{SO}_{4}+2 \mathrm{HCl} \\
2 \mathrm{NaCl}+\mathrm{SO}_{2}+\mathrm{O}_{2} \longrightarrow \mathrm{Na}_{2} \mathrm{SO}_{4}+\mathrm{Cl}_{2} \\
4 \mathrm{NaCl}+2 \mathrm{SO}_{2}+2 \mathrm{H}_{2} \mathrm{O}+\mathrm{O}_{2} \longrightarrow 2 \mathrm{Na}_{2} \mathrm{SO}_{4}+4 \mathrm{HCl}
\end{gathered}
$$

The above analysis shows that chloride and its reaction products $\mathrm{HCl}$ and $\mathrm{Cl}_{2}$ are the main causes of the hightemperature corrosion to metal heating surfaces in boilers. The main factor leading to corrosion to metal heating surfaces is that $\mathrm{HCl}$ reacts directly with the heating surface metal, consequently accelerates the oxidization of metal alloys, and then results in corrosion which is active oxidation corrosion [24]. $\mathrm{Cl}_{2}$, which is similar to the catalyst, has almost no consumption in the corrosion process [25]. If $\mathrm{HCl}$ and $\mathrm{Cl}_{2}$ are supplied constantly, the recurrent corrosion will 
be always going on to damage the iron and its compounds and seriously endangers the operation safety of boiler equipment.

\section{Experimental System and Experimental Method}

3.1. Experimental System. The experimental system of chlorine corrosion on heating surfaces is illustrated in Figure 1, which consists of gas distribution device, hightemperature tube reactor, temperature control unit, and absorption apparatus for tail gas. The gas distribution device provides the simulated flue gas for experiment requirement. The proportion of the components of simulated flue gas is controlled by regulating the gas flow from 3 gas cylinders. The gases flowing out of gas cylinders are mixed in the gas mixing device sufficiently and then feed into the hightemperature tube reactor to simulate flue gas atmosphere in the area of superheater. In the high-temperature tube reactor, the silicon-carbon tube acts as a heating element with built-in corundum tube forming experimental closed flattemperature zone. Metal specimens in porcelain combustion boat are put into the closed flat-temperature zone through a sample delivery device. The reaction region in the hightemperature tube reactor keeps the temperature constant with a temperature controller to simulate the temperature in the area of superheater. In the temperature controller, the temperature ranging from indoor to $1600^{\circ} \mathrm{C}$ is measured by platinum-rhodium platinum thermocouples, and automatic temperature accommodometer is used for data display and temperature control. A large amount of $\mathrm{HCl}$ gas containing in simulated flue gas after the reaction is completely absorbed by absorber bottle with $\mathrm{NaOH}$ solution in case of personnel poisoning and environment polluted.

3.2. Experimental Samples. The biomass samples are straw biomass including corn stalks and wheat stalks in Shandong Province, and coal sample is lean coal. Before the experiment, the biomass and coal samples were ground into powder of 200 mesh by using a small coal mill and an electric vibrating screen and dried in the drying oven under the temperature of $105^{\circ} \mathrm{C}$. The preparation of coal ash is accorded with the method in the coal quality analysis standard GB/T212-2001, and the standard ASTM E1755-01 should be used for the preparation of biomass ash. The proximate analysis and ultimate analysis of biomass samples and coal sample, and ultimate analysis of ash samples are shown in Tables 1 and 2, respectively. The cofiring ash samples in the experiment are made of mixtures of biomass ash and coal ash obtained with the above methods. The metal specimen is made of T91 steel which is commonly used on heat delivery surface of superheater in boilers and has high allowable stress, endurance strength, fatigue strength, thermal conductivity, and well corrosion resistance [26]. The chemical contents of T91 steel are listed in Table 3.

3.3. Experimental Conditions. The cofiring ash samples of coal and biomass are made of mixture of biomass ash and coal ash based on the weight percentage of fuel before burning. The blending proportions of biomass are $0 \%, 20 \%$, $50 \%$, and $100 \%$, and under normal conditions that is $50 \%$. In the course of experiments, $\mathrm{O}_{2}$ concentration is $6 \%, \mathrm{CO}_{2}$ concentration is $12 \%, \mathrm{HCl}$ concentration is $500 \mu \mathrm{L} \cdot \mathrm{L}^{-1}$, and $\mathrm{N}_{2}$ is used as balance gas to keep stable flow of mixing gas which is $50 \mathrm{ml} \cdot \mathrm{min}^{-1}$. When the experimental conditions changed, the $\mathrm{HCl}$ concentration ranges are $0,200,300$, and $500 \mu \mathrm{L} \cdot \mathrm{L}^{-1}$. The ranges of temperature are $450,500,550,600$, and $650^{\circ} \mathrm{C}$, and normal condition is $600^{\circ} \mathrm{C}$.

3.4. Experimental Methods. Before the experiment, the metal pipe used on the heat delivery surface of superheater in boilers was made into specimens of $30 \mathrm{~mm} \times 8 \mathrm{~mm} \times 4 \mathrm{~mm}$. The specimens were successively polished smoothly by sandpaper of 200 mesh and 1000 mesh, and the size of specimens was measured accurately with vernier calipers in order to calculate the surface area. First, the specimens were put into absolute ethyl alcohol to clean and degrease, and their surfaces were blotted up with filter paper. Then, the specimens were put into the drying oven under the temperature of $105^{\circ} \mathrm{C}$. After 30 minutes, the specimens were taken out and their weights were measured. Then, the specimens were coated with cofiring ash samples fasten with absolute ethyl alcohol on the surface and put into the drying oven again to dry for 20 minutes under the temperature of $105^{\circ} \mathrm{C}$, and finally taken out to be used for experiments.

The coated metal specimens along with porcelain combustion boats were put into the flat-temperature zone of the high-temperature tube reactor. The experiments on static oxidation were carried out, and method of corrosion mass gain was used to determine the extent of corrosion to metal. According to the results of previous experimental studies, the extent of corrosion to metal specimens had great growth in the early 20 hours and tended to stable after 30 hours, and hence, the total experimental time of corrosion to metal specimens was determined to be 30 hours, metal specimens were weighed for every 6 hours, and weighing time is controlled within 20 minutes to ensure that each weighing interval is equal.

\section{Results and Discussion}

\subsection{Characteristics of Chlorine Corrosion}

4.1.1. Analysis of Reaction Characteristics of Corrosion Chloride. The corrosion mechanism of the metal heating surface shows that a large amount of chloride in the ash deposition on the superheater and gaseous chlorine released during the combustion are the main reasons for the corrosion to the heating surface in boiler. Gaseous chlorine can directly react with the heated surface metal, and there are two ways for alkali metal chloride corrosion: first, it will react with $\mathrm{SO}_{2}$ in flue gas to form sulfate near the metal surface, and the reaction products $\mathrm{HCl}$ and $\mathrm{Cl}_{2}$ cause active oxidative corrosion which can exacerbate the metal corrosion; the second is to form a low-temperature eutectic with other corrosion products, resulting in the oxide layer on metal surface melting and exacerbating the corrosion. The high- 


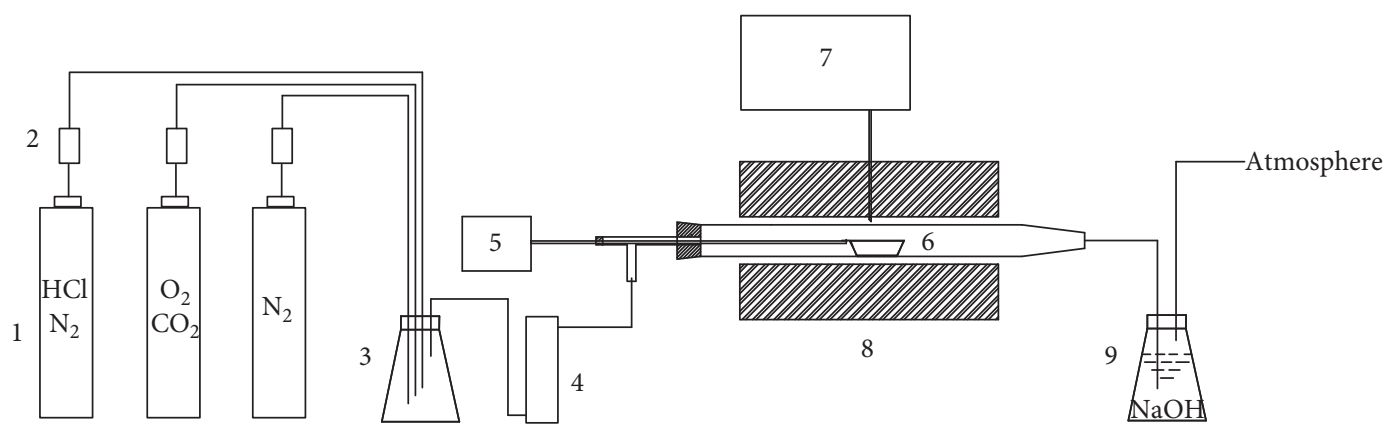

FiguRE 1: Experimental system for chlorine corrosion to metal heat delivery surfaces. (1) gas cylinders; (2) gas flowmeters; (3) gas mixing device; (4) dryer; (5) sample delivery device; (6) porcelain combustion boat; (7) temperature controller; (8) high-temperature tube reactor; (9) absorber bottle.

Table 1: Proximate analysis and ultimate analysis of biomass samples and coal sample (air-dried basis)/wt.\%.

\begin{tabular}{lccccccrr}
\hline \multirow{2}{*}{ Sample } & \multirow{2}{*}{ Symbol } & \multicolumn{4}{c}{ Proximate analysis } & \multicolumn{4}{c}{ Ultimate analysis } \\
& & $\mathrm{M}_{\mathrm{ad}}$ & $\mathrm{A}_{\mathrm{ad}}$ & $\mathrm{V}_{\mathrm{ad}}$ & $\mathrm{FC}_{\mathrm{ad}}$ & $\mathrm{C}_{\mathrm{ad}}$ & $\mathrm{H}_{\mathrm{ad}}$ & $\mathrm{N}_{\mathrm{ad}}$ \\
\hline Corn stalks & $\mathrm{CS}$ & 6.35 & 5.08 & 68.33 & 20.24 & 42.95 & 6.65 & 0.87 \\
Wheat stalks & $\mathrm{WS}$ & 5.44 & 10.82 & 64.03 & 19.71 & 40.27 & 6.34 & 0.68 \\
Lean coal & $\mathrm{LC}$ & 1.43 & 33.74 & 12.99 & 51.84 & 55.41 & 2.97 & 0.96 \\
\hline
\end{tabular}

${ }^{*}$ M: moisture; A: ash; V: volatile matter; FC: fixed carbon.

TABLE 2: Ultimate analysis of ash samples/wt.\%.

\begin{tabular}{lcccccccccc}
\hline Sample & $\mathrm{Na}$ & $\mathrm{Mg}$ & $\mathrm{Al}$ & $\mathrm{Si}$ & $\mathrm{P}$ & $\mathrm{S}$ & $\mathrm{Cl}$ & $\mathrm{K}$ & $\mathrm{Ca}$ & $\mathrm{Fe}$ \\
\hline Corn stalk ash & 0.84 & 6.88 & 0.21 & 5.53 & 1.73 & 1.15 & 34.90 & 45.62 & 2.79 & 0.35 \\
Wheat stalk ash & 1.16 & 4.22 & 1.03 & 31.38 & 1.98 & 4.06 & 15.39 & 32.70 & 8.08 & 0.00 \\
Lean coal ash & 1.21 & 2.66 & 27.15 & 56.32 & 0.49 & 0.33 & 0.71 & 1.45 & 2.22 & 7.46 \\
\hline
\end{tabular}

TABle 3: Chemical contents of T91 steel/wt.\%.

\begin{tabular}{lccccccccccc}
\hline $\mathrm{C}$ & $\mathrm{S}$ & $\mathrm{P}$ & $\mathrm{Si}$ & $\mathrm{Mn}$ & $\mathrm{Cr}$ & $\mathrm{Mo}$ & $\mathrm{V}$ & $\mathrm{Nb}$ & $\mathrm{N}$ & $\mathrm{Al}$ & $\mathrm{Ni}$ \\
\hline $0.08 \sim 0.12$ & $\leq 0.01$ & $\leq 0.02$ & $0.20 \sim 0.50$ & $0.30 \sim 0.60$ & $8.00 \sim 9.50$ & $0.85 \sim 1.05$ & $0.18 \sim 0.25$ & $0.06 \sim 0.10$ & $0.03 \sim 0.07$ & $\leq 0.04$ & $\leq 0.40$ \\
\hline
\end{tabular}

temperature tube reactor was used to simulate high-temperature environment in the area of superheater. Cofiring ash of coal and biomass served as ash deposition was coated on the surface of metal specimens in order to simulate the effect of ash deposition on corrosion to metal heating surfaces, and mixing gas consisting of $\mathrm{HCl}, \mathrm{O}_{2}, \mathrm{CO}_{2}$, and $\mathrm{N}_{2}$ was used to simulate flue gas atmosphere in boilers. The issues of chlorine corrosion to metal heating surfaces of superheater in boilers were experimentally studied in this paper, with simulating the operating condition of metal heating surfaces of superheater in boilers.

Figures 2 and 3 illustrate the mass gain curves of corrosion to T91 steel specimens coated with cofiring ash of coal and biomass blended to coal with different percentages. It can be found from the above figures that the mass gains of corrosion to metal specimens increase along with the lapse of time. The mass gains of corrosion to metal specimens increased rapidly at the initial stage, which was a rapid corrosion stage, and then gradually slowed down and tend to be flat at the later stage. The curves of corrosion mass gains accorded with parabola.
The corrosion process of the samples is analyzed as follows: when iron or iron alloy is exposed to a high-temperature oxidation environment, the outer layer of the metal will gradually oxidize into a stable and dense oxide film. But the alkali metal chloride in the ash reacts with the oxide film on the metal surface, and releasing $\mathrm{Cl}_{2}$, resulting in the destruction of the metal oxide film. The $\mathrm{Cl}_{2}$ can penetrate the protective oxide film, diffuse to the interface between oxide film and metal, and react with the metal to form a metal chloride. The metal chloride has a lower melting point. When the temperature of the metal tube is high, metal chloride will evaporate and diffuse to the surface of the oxide film, react with the oxygen in flue gas, and gradually form a loose oxide layer. The oxide layer cannot protect the metal from further corrosion. This reaction generates $\mathrm{Cl}_{2}$ again, and $\mathrm{Cl}_{2}$ returns to the metal surface through the loose oxide layer, so that the corrosion process continues. In the initial stage, there are more alkali metal chlorides in ash, and the corrosion rate is fast; as the reaction continues, the alkali metal chloride content gradually depletes, and the corrosion reaction rate also gradually decreases. 


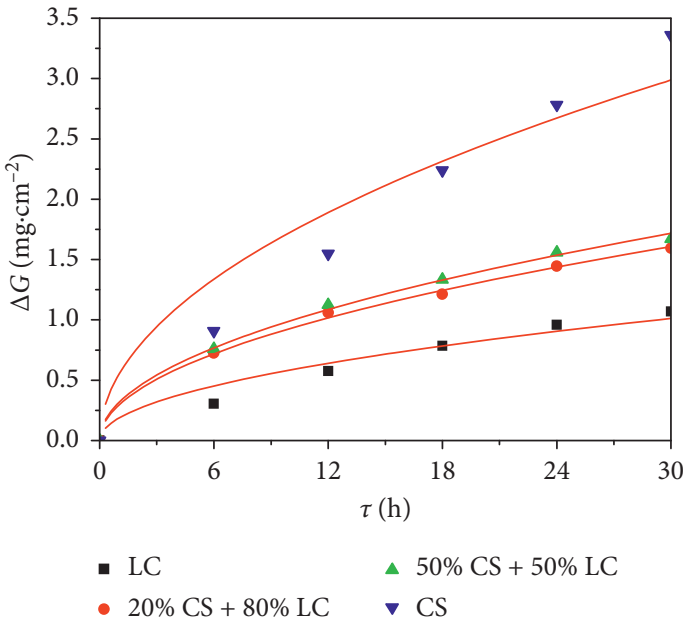

FIGURE 2: Mass gain curves of corrosion to metal specimens coated with cofiring ash of coal and biomass (corn stalks) blended to coal with different percentages.

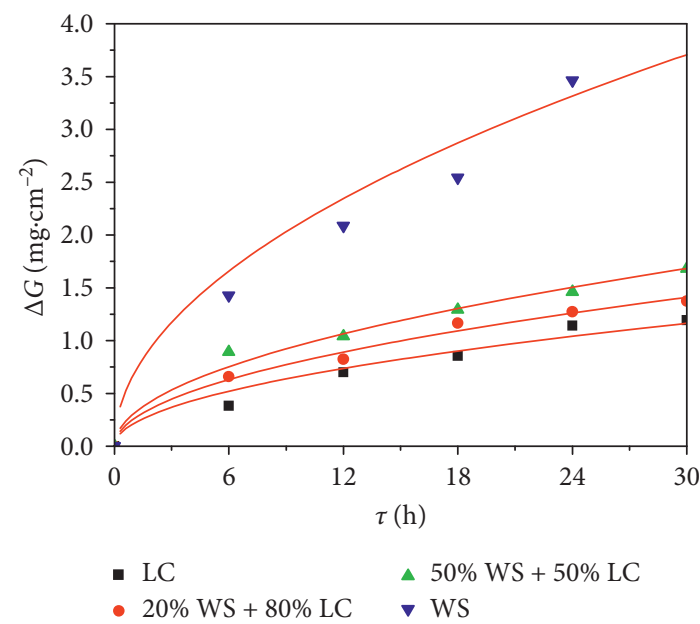

FIgURe 3: Mass gain curves of corrosion to metal specimens coated with cofiring ash of coal and biomass (wheat stalks) blended to coal with different percentages.

It can be also found from the above figures that with increasing the percentage of straw biomass blended to coal, the rate of corrosion to metal specimens increases proportionately, and corrosion to metal specimens was most serious when all was straw biomass. The reason can be explained as follows. During cofiring of coal and straw biomass, the content of residual chloride in ash deposition increased with the straw biomass blended to coal. Chloride in ash deposition will participate in salinization to form aluminosilicate and release $\mathrm{HCl}$ from the metal surface, thus accelerating the process of corrosion reaction and increasing the rate of chlorine corrosion.

\subsubsection{Effects of Temperature on Chlorine Corrosion} Characteristics. Temperature had a significant influence on corrosion to metal. The operating experiences from foreign biomass power plant showed that when the temperature of steam in superheater was high, the serious corrosion would occur generally on the pipe wall of superheater [27], but when the temperature of steam in superheater was low (such as $450^{\circ} \mathrm{C}$ ), the serious corrosion was not found [28]. Figure 4 illustrates the mass gain curves of corrosion to ash-coated metal specimens under different temperatures. It can be found that the rate of corrosion to metal specimens increases constantly with temperature increasing. When the temperature was below $600^{\circ} \mathrm{C}$, it had a little influence on corrosion to metal specimens and the rate of corrosion to metal specimens increased slowly. But when the temperature exceeded $600^{\circ} \mathrm{C}$, the rate of corrosion to metal specimens increased significantly. The reason is mainly due to the different corrosion mechanism.

In the initial stage of the corrosion, all elements in the metal are jointly participated in the reaction. As a crucial element of the alloy, $\mathrm{Cr}$ can preferentially react with oxygen and form a dense and adhesive oxide film, so that the corrosion resistance of metal can be enhanced. However, when the temperature increases, the diffusion velocity of $\mathrm{C}$ in the interior of the metal grain is greater than Cr. The formation and precipitation of carbides in the metal base cause local chromium deficiency near the grain boundary. Alkali metal chloride such as $\mathrm{NaCl}$ from deposits easily reacts with metal carbides to generate $\mathrm{Cl}_{2}$, which causes severe intergranular corrosion. Intergranular corrosion spreads inward along the interface between metal grains, which greatly reduces the mechanical strength of the metal. The higher the grain boundary carbon content, the more severe this effect. It is observed from the corrosion layer on the metal surface that with the increase in temperature, the corrosion layer became thicker and serious pitting corrosion occurred gradually on the surface.

In addition, when the temperature is low, the metal corrosion is mainly common oxidative corrosion. Once the temperature increases, the alkali metal sulfate in the ash deposit becomes a molten liquid phase on the surface of the oxide layer, which rapidly exacerbates the corrosion. During the cofiring of biomass and coal, due to the sulfation reaction, there is a large amount of sulfate in the ash deposition, and it also contains some alkali metal chloride. Alkali metal chlorides in ash deposition may cause the melting point of low-temperature comelts to decrease further. The metal base is easier to be corroded by the $\mathrm{HCl}$ and $\mathrm{SO}_{2} / \mathrm{SO}_{3}$ in the surrounding gas phase due to the melting and destruction of the protective oxide layer, which makes the corrosion exacerbate.

\subsubsection{Effects of $\mathrm{HCl}$ Concentration on Chlorine Corrosion} Characteristics. The views on the effect of $\mathrm{HCl}$ on chloride corrosion to metal were different. Montgomery and Larsen considered that the corrosiveness of $\mathrm{HCl}$ was lower than the corrosiveness of $\mathrm{KCl}$ in depositing on the surface of the oxidation layer [29]. Lith et al. found from experiments that when there was the element chlorine in ash deposition, the presence of $\mathrm{HCl}$ was not a necessary condition for the chlorine corrosion, but it can accelerate chlorine corrosion [30]. Yin and $\mathrm{Wu}$ found by the study on corrosion of 


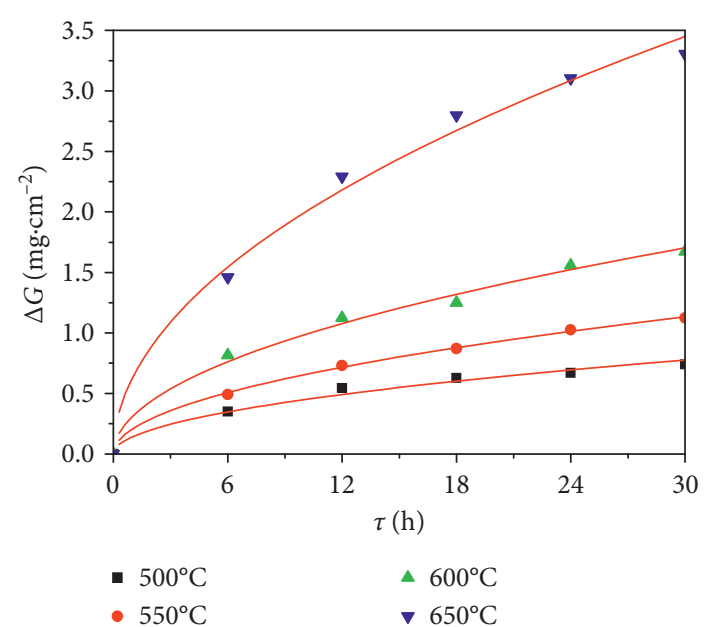

Figure 4: Mass gain curves of corrosion to ash-coated metal specimens under different temperatures.

chlorine in biomass that the rate of corrosion to metal increased proportionally with the increase in the concentration of $\mathrm{HCl}$ [31]. Figure 5 illustrates the mass gain curves of corrosion to ash-coated metal specimens under different concentrations of $\mathrm{HCl}$. It can be found that if there is no $\mathrm{HCl}$ in the gas phase, mass gains of metal specimens vary a little and the rate of corrosion is very low. With the increase in the concentration of $\mathrm{HCl}$, mass gains of metal specimens vary a lot and the rate of corrosion increases rapidly. Because the oxide layer on the metal surface cannot block the penetration of $\mathrm{HCl}, \mathrm{HCl}$ can penetrate the cracks or pores on the metal surface and contact and react with metal alloy elements ( $\mathrm{Fe}, \mathrm{Cr}$, and $\mathrm{Ni}$ ). With the increase of $\mathrm{HCl}$, the chlorine pressure difference between atmosphere/oxide film interface and oxide film/metal interface increases, which enhances the kinetic force of $\mathrm{HCl}$ diffusion to the metal surface, so $\mathrm{HCl}$ can easily pass through the oxide film and accelerate corrosion. In addition, the higher the concentration of $\mathrm{HCl}$, the stronger the active oxidation. As the $\mathrm{HCl}$ concentration increases, the mass gain of the metal sample changes greatly, and the corrosion rate increases rapidly.

\subsection{Reaction Kinetics of Chlorine Corrosion}

4.2.1. The Basic Equation of Corrosion Reaction Kinetics. The main task in the study of chemical reaction kinetics is how to determine the process mechanism of chemical reaction and relevant reaction kinetics parameters [32]. In experimental study on characteristics of chlorine corrosion to metal heating surfaces, every experiment of chlorine corrosion to metal specimens was carried out under constant temperature condition. Hence, the reaction rates of corrosion to metal specimens were described by constant temperature and heterogeneous reaction kinetics equation [33]:

$$
\frac{\mathrm{d} \alpha}{\mathrm{d} \tau}=k \cdot f(\alpha)
$$

In (14), $\tau$ is the reaction time, $k$ is the reaction rate constant, and $\alpha$ is the conversion rate from reactants to

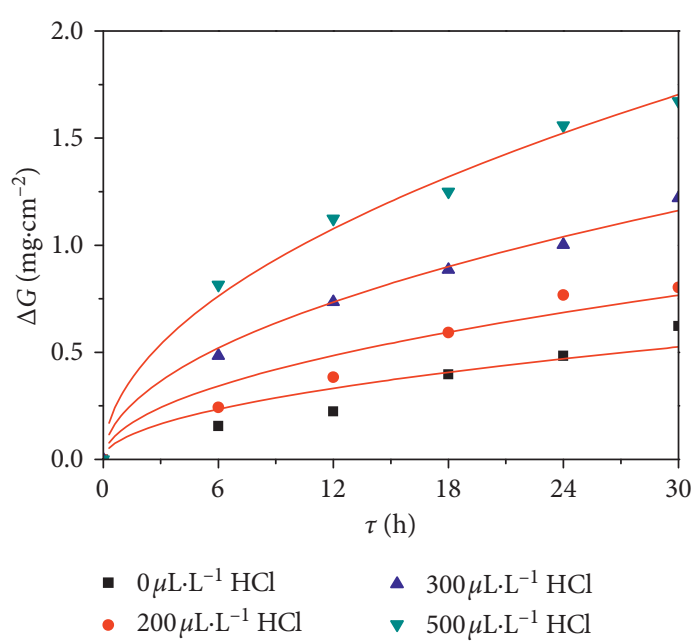

FIgURE 5: Mass gain curves of corrosion to ash-coated metal specimens under different concentrations of $\mathrm{HCl}$ in the gas phase.

resultants in the time of $\tau . \alpha=w-w_{0} / w_{\infty}-w_{0}, w_{0}$ and $w_{\infty}$ are the initial and final weight of specimens, respectively, $w$ is the weight of specimens in the time of $\tau$. $f(\alpha)$ is the reaction kinetics model function which reveals the mechanism of chemical reaction.

The relationship between reaction rate constant $k$ and temperature $T$ is expressed by Arrhenius law [34]:

$$
k=A \exp \left(-\frac{E}{R_{\mathrm{m}} T}\right) .
$$

In the (15), $A$ is the frequency factor, $E$ is the activation energy, $T$ is the reaction temperature, and $R_{\mathrm{m}}$ is the universal gas constant and its value is $8.3145 \mathrm{~J} \cdot \mathrm{mol}^{-1} \cdot \mathrm{K}^{-1}$.

The basic equation of reaction kinetics of corrosion to metal is obtained through substituting (15) into (14):

$$
\frac{\mathrm{d} \alpha}{\mathrm{d} \tau}=A \exp \left(-\frac{E}{R_{\mathrm{m}} T}\right) f(\alpha) .
$$

4.2.2. Determination of the Optimal Dynamic Model Function. The reaction kinetics model function $f(\alpha)$ expresses a certain functional relationship to follow between the rate of chemical reaction and conversion rate $\alpha$ and represents the chemical reaction mechanism. Its corresponding integral form is defined as follows:

$$
G(\alpha)=\int_{0}^{\alpha} \frac{\mathrm{d} \alpha}{f(\alpha)} .
$$

The correctness of reaction kinetics model function had great effects on kinetics parameters of reaction. The characteristics of chemical reaction kinetics can be analyzed by various methods to determine the correct reaction kinetics model, such as isothermal method, nonisothermal singlescan method, kinetic compensation effect method, and nonisothermal multiple scan method [35]. The isothermal method will be used to solve the following problems because experiments of chlorine corrosion to metal specimens are carried out under constant temperature condition. 
TABle 4: The conversion rate of metal specimens at different times.

\begin{tabular}{llccccc}
\hline$t\left({ }^{\circ} \mathrm{C}\right)$ & & & $\alpha$ & & \\
& 0 & $6 \mathrm{~h}$ & $12 \mathrm{~h}$ & $16 \mathrm{~h}$ & $24 \mathrm{~h}$ & 0.906 \\
\hline 500 & 0 & 0.472 & 0.735 & 0.849 & 0.913 & 1.000 \\
550 & 0 & 0.438 & 0.650 & 0.775 & 0.932 \\
600 & 0 & 0.454 & 0.672 & 0.847 & 0.939 & 1.000 \\
650 & 0 & 0.442 & 0.693 & 1.000 \\
\hline
\end{tabular}

TABLE 5: Model functions of reaction kinetics.

\begin{tabular}{lccc}
\hline Model functions & Symbol & $f(\alpha)$ & $G(\alpha)$ \\
\hline One-dimensional diffusion model & D1 & $(1 / 2) \alpha^{-1}$ & $\alpha$ \\
Two-dimensional diffusion model & D2 & {$[-\ln (1-\alpha)]^{-1}$} & $\alpha+(1-\alpha) \ln (1-\alpha)$ \\
Three-dimensional diffusion model (Jander) & D3 & $(3 / 2)(1-\alpha)^{2 / 3}\left[1-(1-\alpha)^{1 / 3}\right]^{-1}$ & {$\left[1-(1-\alpha)^{1 / 3}\right]^{2}$} \\
Three-dimensional diffusion model (Ginstling-Brounstein) & D & $(3 / 2)\left[(1-\alpha)^{-1 / 3}-1\right]^{-1}$ & $1-(2 / 3) \alpha-(1-\alpha)^{2 / 3}$ \\
Secondary nucleation and growth reaction & A2 & $2(1-\alpha)[-\ln (1-\alpha)]^{1 / 2}$ & {$[-\ln (1-\alpha)]^{1 / 2}$} \\
Secondary phase interface reaction & R2 & $2(1-\alpha)^{1 / 2}$ & $1-(1-\alpha)^{1 / 2}$ \\
\hline
\end{tabular}

The isothermal method is relatively simple, and the model fitting method is generally used to fit experimental data with reaction kinetics model functions. At a certain constant temperature, the reaction rate constant $k$ is constant, so it can be separated with $f(\alpha)$ or $G(\alpha)$ by substituting (16) into (17):

$$
G(\alpha)=\int_{0}^{\tau} A \exp \left(-\frac{E}{R_{\mathrm{m}} T}\right) \cdot \mathrm{d} \tau=k(T) \tau .
$$

From (18), it can be seen that $G(\alpha)$ has a linear relationship with time $\tau$, and the slope of the line is the reaction rate constant $k$. A set of data of $\alpha$ and $\tau$ under constant temperature condition is selected to substitute into tentative $G(\alpha)$ and draw the relationship curve of $G(\alpha)$ versus time $\tau$. If $f(\alpha)$ corresponded to $G(\alpha)$ has a optimal linear relationship with time $\tau$, it is deemed to be the optimal reaction kinetics model function.

4.2.3. Establishment of Reaction Kinetics Equations of Chlorine Corrosion. The purpose of the study on reaction kinetics of chlorine corrosion to metal is to determine the optimal kinetics model function $f(\alpha)$, calculate the reaction kinetics parameters $A, E$, and the reaction rate constant $k$, then put forward reaction rate function, and finally obtain reaction kinetics equations to quantitatively represent the process of chlorine corrosion reaction. Hence, the characteristics of reaction kinetics of chlorine corrosion to metal were studied in this paper with isothermal method basing on experimental data listed in Figure 4. Table 4 getting from Figure 4 shows the conversion rate of metal specimens at different times under certain temperature.

The reaction kinetics model functions listed in Table 5 were chosen to use for tentative model function to fit model. The data in Figure 4 were, respectively, substituted into $G(\alpha)$ corresponding to six reaction kinetics model functions selected in common use, to obtain the value of $G(\alpha)$ at different times $\tau$ under certain temperature. The relationship curves of $G(\alpha)$ versus $\tau$ were drawn respectively and fitted linearly, and then $f(\alpha)$ corresponded to $G(\alpha)$, which has optimal linear relationship with time $\tau$, was deemed to be the optimal reaction kinetics model function.

By means of drawing respectively and fitting linearly the relationship curves of $G(\alpha)$ versus $\tau$, the optimal reaction kinetics model function was obtained to be $G(\alpha)$ and $f(\alpha)$ corresponding with one-dimensional diffusion model. Only the relationship curves of $G(\alpha)$ versus $\tau$ fitted linearly with one-dimensional diffusion model are given in Figure 6.

(15) was taken logarithm on both sides:

$$
\ln k=\ln A-\frac{E}{R_{\mathrm{m}} T}
$$

From (19), it can be seen that the relationship between $\ln k$ and $T^{-1}$ was linear and the parameters $A$ and $E$ were calculated through the intercept $\ln A$ and slope $-E / R_{\mathrm{m}}$.

The values of $k$ under certain temperature were obtained from fitting curves in Figure 6 and corresponding values of $T^{-1}$ and $\ln k$ are calculated in Table 6 . Basing on the data in the above table, the relationship curve of $\ln k$ versus $T^{-1}$ was drawn and fitted linear and is shown in Figure 7. The fitting relationship equation was finally obtained as follows: $\ln k=-3.1386-205.5553 T^{-1}$, and the correlation coefficient of fitting linear was $R^{2}=0.9814$.

By means of the above fitted linear relationship equation, the reaction kinetics parameters $A$ and $E$ were calculated. The results of $A=0.04334$ and $E=1709.08954 \mathrm{~J} \cdot \mathrm{mol}^{-1}$ were, respectively, derived from $\ln A=-3.1386$ and $E / R_{\mathrm{m}}=205.5553$.

The value of $A$ and $E$ and the optimal model function $f(\alpha)=(1 / 2) \alpha^{-1}$ were substituted into (16) to obtain following reaction kinetics equations of chlorine corrosion to metal specimens:

$$
\frac{\mathrm{d} \alpha}{\mathrm{d} \tau}=0.02167 \exp \left(\frac{-205.5553}{T}\right) \cdot \alpha^{-1} .
$$

The time integral of (20) was taken. Because the experiments were carried out under constant temperature, temperature was not a function of time and therefore considered as constant. At the time of $\tau=0$, the experiments have not started, and the conversion rate was zero. In other 


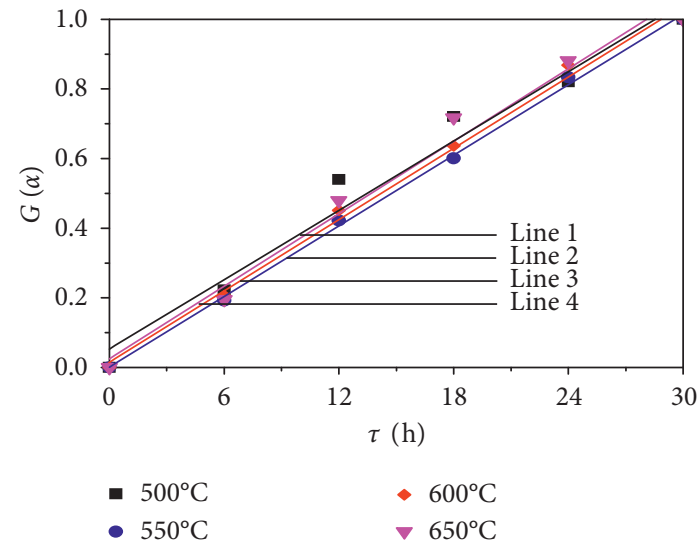

FIgURE 6: Fitting curves of $G(\alpha)$ versus $\tau$ with one-dimensional diffusion model. Line $1-500^{\circ} \mathrm{C}: \quad G(\alpha)=0.05258+0.03321 \tau$ and $R^{2}=0.9655$; Line $2-550^{\circ} \mathrm{C}: G(\alpha)=0.00071+0.03383 \tau$ and $R^{2}=0.9980$; Line $3-600^{\circ} \mathrm{C}: G(\alpha)=0.01485+0.03416 \tau$ and $R^{2}=0.9934$; Line $4-650^{\circ} \mathrm{C}$ : $G(\alpha)=0.02463+0.03474 \tau$ and $R^{2}=0.9789$.

TABLE 6: Reaction rate constants $k$ under certain temperature.

\begin{tabular}{lcccc}
\hline$t\left({ }^{\circ} \mathrm{C}\right)$ & $T(\mathrm{~K})$ & $T^{-1}\left(\mathrm{~K}^{-1}\right)$ & Reaction rate constant $k$ & $\ln k$ \\
\hline 500 & 773 & 0.001294 & 0.03321 & -3.4049 \\
550 & 823 & 0.001215 & 0.03383 & -3.3864 \\
600 & 873 & 0.001145 & 0.03416 & -3.3767 \\
650 & 923 & 0.001083 & 0.03474 & -3.3599 \\
\hline
\end{tabular}

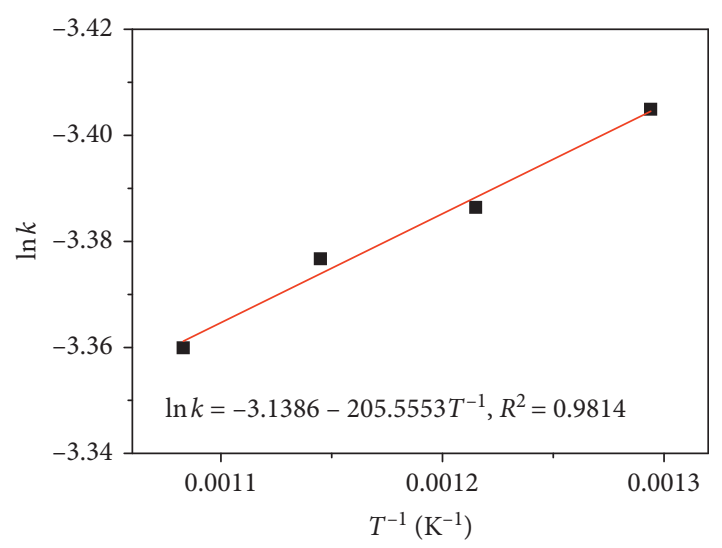

Figure 7: Fitting curve of $\ln k$ versus $T^{-1}$. Fitting line: $\ln k=-3.1386-205.5553 T^{-1}, R^{2}=0.98114$.

words, if $\tau=0$, then $\alpha=0$. The equation of the conversion rate $\alpha$ through integral is obtained as follows:

$$
\alpha=0.2082 \exp \left(\frac{-102.7777}{T}\right) \cdot \tau^{-(1 / 2)} .
$$

\section{Conclusions}

During cofiring of coal and biomass, alkali metal chlorides, $\mathrm{HCl}$ and $\mathrm{Cl}_{2}$, cause high-temperature corrosion to metal heating surfaces in boilers. $\mathrm{HCl}$ is the main factor leading to corrosion to metal heating surfaces, which can directly react with metal heating surfaces and accelerate oxidization of alloy. $\mathrm{Cl}_{2}$ has almost no consumption in the process of corrosion, which was similar to the catalyst. If $\mathrm{HCl}$ and $\mathrm{Cl}_{2}$ were supplied constantly, the recurrent reaction process of corrosion will be always going on, and thus, it is of repetitive features. If chlorides coexist with sulfur oxides, the process of high-temperature corrosion will greatly be accelerated.

The mass gain curves of metal accorded with parabola, and the degree of corrosion is greatly affected by the blending ratio of biomass. At the initial stage, there was a rapid corrosion stage, the corrosion reaction rate was high, and the protective oxidation layer was soon formed on the surface of metal specimens. As the oxidation layer gradually becomes thicker, the corrosion reaction rate gradually slowed down and tends to be flat at the later stage. With the percentage of straw biomass blended to coal increasing, due to the increasing the content of residual chloride in ash deposition, the rate of corrosion to metal specimens increases proportionately, and corrosion to metal specimens was most serious when all was straw biomass.

Temperature and concentration of $\mathrm{HCl}$ in the gas phase also had a significant influence on corrosion to metal. With the increase in temperature, the rate of corrosion to metal increased constantly. When the temperature was below $600^{\circ} \mathrm{C}$, the rate of corrosion to metal specimens increased slowly. But when the temperature exceeded $600^{\circ} \mathrm{C}$, the rate of corrosion to metal specimens increased significantly. The rate of corrosion to metal specimens rapidly increased with the increase in the concentration of $\mathrm{HCl}$ in the gas phase.

Using model fitting methods, the analyses on reaction kinetics of chlorine corrosion to metal heating surfaces were carried out under constant temperature condition. It is found that the experimental data were fitted well with one-dimensional diffusion model, and therefore, optimal kinetic model function and corresponding kinetics parameters of chlorine corrosion reaction were obtained, and finally, the reaction kinetics equation of chlorine corrosion to metal was established:

$$
\frac{\mathrm{d} \alpha}{\mathrm{d} \tau}=0.02167 \exp \left(\frac{-205.5553}{T}\right) \cdot \alpha^{-1} .
$$

\section{Notations}

Explanation of symbols

A: $\quad$ Frequency factor, $\mathrm{s}^{-1}$

E: $\quad$ Activation energy, $\mathrm{J} \cdot \mathrm{mol}^{-1}$

$f(\alpha)$ : Reaction kinetics model function

$G(\alpha)$ : Integral form of reaction kinetics model function

$k: \quad$ Reaction rate constant

$\mathrm{R}_{\mathrm{m}}$ : $\quad$ Universal gas constant, $8.3145 \mathrm{~J} \cdot \mathrm{mol}^{-1} \cdot \mathrm{K}^{-1}$

T: $\quad$ Reaction temperature, $\mathrm{K}$

$w$ : Weight of specimens in the time of $\tau, \mathrm{mg}$

$\mathrm{w}_{0}, \mathrm{w}_{\infty}$ : Initial and final weight of specimens, respectively, $\mathrm{mg}$

$\alpha: \quad$ Conversion rate from reactants to resultants in the time of $\tau$

$\Delta G: \quad$ Mass gain of corrosion to metal specimens, $\mathrm{mg} \cdot \mathrm{cm}^{-2}$

$\tau: \quad$ Reaction time, $\mathrm{h}$ 


\author{
Subscript \\ 0: Initial time \\ $\infty$ : Final time.
}

\section{Data Availability}

The data used to support the findings of this study are available from the corresponding author upon request.

\section{Conflicts of Interest}

The authors declare that there are no conflicts of interest regarding the publication of this paper.

\section{Acknowledgments}

This work was supported by Shandong Provincial Natural Science Foundation, China (ZR2017MEE009).

\section{References}

[1] S. Xiong, J. Burvall, H. Orberg et al., "Slagging characteristics during combustion of corn stovers with and without kaolin and calcite," Energy \& Fuels, vol. 22, no. 5, pp. 3465-3470, 2008.

[2] J. B. Królczyk, A. Rezwiakow, and M. Tukiendorf, "Mixing of biomass and coal in a static mixer as an example of technological solutions involving implementation of renewable energy sources," Ecological Chemistry and Engineering $S$, vol. 21, no. 4, pp. 685-696, 2015.

[3] J. Mao, "Coal fired coupling biomass power generation," Distributed Energy Resources, vol. 2, no. 5, pp. 47-54, 2017.

[4] P. Basu, J. Butler, and M. A. Leon, "Biomass co-firing options on the emission reduction and electricity generation costs in coal-fired power plants," Renewable Energy, vol. 36, no. 1, pp. 282-288, 2011.

[5] L. L. Baxter, "Ash deposition during biomass and coal combustion: a mechanistic approach," Biomass and Bioenergy, vol. 4, no. 2, pp. 85-102, 1993.

[6] A. L. Robinson, H. Junker, and L. L. Baxter, "Pilot-scale investigation of the influence of coal-biomass cofiring on ash deposition," Energy \& Fuels, vol. 16, no. 2, pp. 343-355, 2002.

[7] T. Nussbaumer, "Combustion and Co-combustion of biomass: fundamentals, technologies, and primary measures for emission reduction," Energy \& Fuels, vol. 17, no. 6, pp. 1510-1521, 2003.

[8] M. Srivastava, J. N. Balaraju, B. Ravisankar, C. Anandan, and V. K. William Grips, "High temperature oxidation and corrosion behaviour of $\mathrm{Ni} / \mathrm{Ni}-\mathrm{Co}-\mathrm{Al}$ composite coatings," Applied Surface Science, vol. 263, no. 24, pp. 597-607, 2012.

[9] C. Berlanga and J. A. Ruiz, "Study of corrosion in a biomass boiler," Journal of Chemistry, vol. 2013, Article ID 272090, 8 pages, 2013.

[10] J. Song, J. Song, and J. Li, "Study on influence of high temperature corrosion and pollutants emission of co-combustion of coal in biomass boiler," Power System Engineering, vol. 31, no. 2, pp. 37-43, 2015.

[11] L. Li, C. Yu, F. Huang, J. Bai, M. Fang, and Z. Luo, "Study on the deposits derived from a biomass circulating fluidized-bed boiler," Energy \& Fuels, vol. 26, no. 9, pp. 6008-6014, 2012.

[12] X. Song, S. Zhu, B. Huang et al., "Study of emission characteristics of chlorine and potassium in biomass combustion,"
Acta Energiae Solaris Sinica, vol. 36, no. 10, pp. 2543-2547, 2015.

[13] C. Yu, Z. Wang, B. Gong et al., "Corrosion characteristics of biomass bolier steel in $\mathrm{KCl}$ contact condition," Journal of Zhejiang University, vol. 48, no. 11, pp. 2046-2052, 2014.

[14] Y. He, Y. Li, H. Zhang et al., "High temperature corrosion behavior of T91 in alkali metal chloride medium," Corrosion and Protection, vol. 36, no. 11, pp. 1021-1025, 2015.

[15] X. Wang, Z. Xu, B. Wei et al., "The ash deposition mechanism in boilers burning Zhundong coal with high contents of sodium and calcium: a study from ash evaporating to condensing," Applied Thermal Engineering, vol. 80, pp. 150-159, 2015.

[16] P. Molcan, G. Lu, T. L. Bris, Y. Yan, B. Taupin, and S. Caillat, "Characterisation of biomass and coal co-firing on a $3 \mathrm{MW}$ th combustion test facility using flame imaging and gas/ash sampling techniques," Fuel, vol. 88, no. 12, pp. 2328-2334, 2009.

[17] X. Wang, Z. Hu, S. Deng, Y. Xiong, and H. Tan, "Effect of biomass/coal co-firing and air staging on NOx emission and combustion efficiency in a drop tube furnace," Energy Procedia, vol. 61, pp. 2331-2334, 2014.

[18] K. Qiu, H. Zhang, H. Zhou, B. Zhou, L. Li, and K. Cen, "Experimental investigation of ash deposits characteristics of co-combustion of coal and rice hull using a digital image technique," Applied Thermal Engineering, vol. 70, no. 1, pp. 77-89, 2014.

[19] Y. Wang, K. Zhang, L. Jiang et al., "Study on sulfur-chlorine synergistic corrosion in biomass and coal co-firing," Journal of Chemical Engineering of Chinese Universities, vol. 29, no. 6, pp. 1422-1429, 2015.

[20] A. Miltner, G. Beckmann, and A. Friedl, "Preventing the chlorine-induced high temperature corrosion in power boilers without loss of electrical efficiency in steam cycles," Applied Thermal Engineering, vol. 26, no. 16, pp. 2005-2011, 2006.

[21] G. Li, S. Guo, and X. Zhao, "High temperature chloridization corrosion on the bio-fuel boiler," Total Corrosion Control, vol. 23, no. 11, pp. 44-45, 2009.

[22] S. Li, W. Yan, and L. Fang, "The mechanism of the high temperature chloridization corrosion on the heat transfer surface of utility boiler," Boiler Manufacturing, vol. 1999, no. 4, pp. 19-23, 1999.

[23] H. Song and H. Zhen, "Study on mechanism of high temperature superheater corrosion of biomass fired boiler," Boiler Manufacturing, vol. 2010, no. 5, pp. 14-18, 2010.

[24] A. Zahs, M. Spiegel, and H. Grabke, "The influence of alloying elements on the chlorine-induced high temperature corrosion of Fe-Cr alloys in oxidizing atmospheres," Materials and Corrosion, vol. 50, no. 10, pp. 561-578, 1999.

[25] N. S. Harding and D. C. O'Connor, "Ash deposition impacts in the power industry," Fuel Processing Technology, vol. 88, no. 11-12, pp. 1082-1093, 2007.

[26] R. Wang, Y. Xu, W. Chen et al., "Performance and application of heat resistant steel T/P91 for supercritical boilers," Modern Metallurgy, vol. 37, no. 3, pp. 1-3, 2009.

[27] M. Montgomery, T. Vilhelmsen, and S. A. Jensen, "Potential high temperature corrosion problems due to co-firing of biomass and fossil fuelsfiring of biomass and fossil fuels," Materials and Corrosion, vol. 59, no. 10, pp. 783-793, 2008.

[28] H. P. Nielsen, F. J. Frandsen, K. Dam-Johansen, and L. L. Baxter, "The implications of chlorine-associated corrosion on the operation of biomass-fired boilers," Progress in 
Energy and Combustion Science, vol. 26, no. 3, pp. 283-298, 2000.

[29] M. Montgomery and O. H. Larsen, "Field test corrosion experiments in Denmark with biomass fuels. Part 2: co-firing of straw and coal," Materials and Corrosion, vol. 53, no. 3, pp. 185-194, 2002.

[30] S. C. V. Lith, F. J. Frandsen, M. Montgomery, T. Vilhelmsen, and S. A. Jensen, "Lab-scale investigation of deposit-induced chlorine corrosion of superheater materials under simulated biomass-firing conditions. Part 1: exposure at $560^{\circ} \mathrm{C}$," Energy \& Fuels, vol. 23, no. 7, pp. 3457-3468, 2009.

[31] J. Yin and Z. Wu, "Corrosive characters of TP347H steel in superheater's atmosphere of biomass-burned boiler," Thermal Power Generation, vol. 38, no. 7, pp. 27-31, 2009.

[32] H. Guo, Applied Chemical Engineering Kinetics, Chemical Industry Press, Shanghai, China, 2003.

[33] N. Ren and J. J. Zhang, "Progress in datum treatment methods of thermal analysis kinetics," Progress in Chemistry, vol. 18, no. 4, pp. 410-416, 2006.

[34] C. Lu and Y. Wang, The Theory and Techniques of Coal Combustion, Seismological Press, Beijing, China, 2001.

[35] R. Hu, S. Gao, and F. Zhao, Thermal Analysis Kinetics, Science Press, Beijing, China, 2008. 